\title{
A State-of-the-Art Systematic Content Analysis of Games for Health
}

\author{
Amy Shirong Lu, $\mathrm{PhD}$, and Hadi Kharrazi, MD, $\mathrm{PhD}^{2}$
}

\begin{abstract}
As the field of games for health continues to gain momentum, it is crucial to document the field's scale of growth, identify design patterns, and to address potential design issues for future health game development. Few studies have explored the attributes and usability features of games for health as a whole over time. We offer the first comprehensive systematic content analysis of digital games for health by examining 1743 health games released between 1983 and 2016 in 23 countries extracted from nine international English health game databases and directories. The majority of these games were developed in the United States (67.18\%) and France (18.59\%). The most popular platforms included web browsers (72.38\%) and Windows (14.41\%). Approximately four out of five $(79.12 \%)$ of the games were available at no cost. We coded 1553 accessible games for an in-depth analysis and further assessed 1303 for usability. Popular health topics represented included: cognitive training (37.41\%), indirect health education (13.33\%), and medical care provision $(9.98 \%)$. Most games $(75.66 \%)$ could be completed within 60 minutes. The main game usability problems identified included a lack of customization, nonskippable contents, and a lack of feedback and instruction to the players. While most of the usability problems have improved as did the software and hardware technology, the players' ability to skip nonplayable contents has become slightly more restricted overtime. Comparison with game efficacy publications suggested that a further understanding of the scope for games for health is needed on a global level.
\end{abstract}

Keywords: Content analysis, Games for healthcare, Games for health, Game usability

\section{Introduction}

A DVANCES IN THE pervasive technology and internet connectivity, and improvements in gaming devices have significantly enhanced the availability and development of serious games, or games designed for a purpose going "beyond entertainment.", By 2020, the projected total market value of serious games will be $\$ 5.45$ billion. ${ }^{2}$ While this number may seem small when compared with the global videogame revenue (more than $\$ 200$ billion), the serious game industry's compound annual growth rate is much higher than the latter's (16.4\% vs. $7.9 \%)$, suggesting much more potential for development. ${ }^{3}$

As an important part of the serious game movement, ${ }^{4}$ recent decades have seen a surge in games for health, or games and gaming technologies designed to improve health and healthcare. ${ }^{5}$ Currently, $67 \%$ of the households in the United States own a device used to play videogames, ${ }^{6} 91 \%$ of children play games and $87 \%$ have a game console at home. ${ }^{7}$ All major console and mobile game companies offer devices that can be used for health purposes, such as active videogaming. ${ }^{8}$ Games for health have been also found to be a powerful technology that improves learning and skills development for health professionals. ${ }^{9-11}$ Multiple conferences dedicated to games for health have been launched and numerous academic articles, books, and journals have been published across multidisciplinary fields.

As games for health have enjoyed an exponential growth, it is crucial to document the field's scale of growth, identify design patterns, and to address potential design issues for future health game development. However, the academic literature on the health games has been limited. Many fundamental questions about the game facts have not been fully explored, such as: How many health games are out there? Where are they made? What kind of games are they? Which health issues do they address? Who are the games designed for? How long does it take to play a health game? How much do they cost? What are persisting usability issues that aspiring health game

\footnotetext{
${ }^{1}$ Health Technology Laboratory, Department of Communication Studies, College of Arts, Media \& Design, Bouvé College of Health Sciences, Northeastern University, Boston, Massachusetts.

${ }^{2}$ Department of Health Policy and Management, Bloomberg School of Public Health, Johns Hopkins University, Baltimore, Maryland.
} 
developers should pay attention to? Few publications have examined the games on a macroscale to answer these questions. Almost all publications have focused on the development and/or application of one or a few specific health games ${ }^{12-16}$ or have described a synthesis of findings of games designed for a certain health issue. ${ }^{17-20}$ The grand picture is still missing.

Efforts to use existing scholarship to paint the grand picture have yielded varied estimations limited by the scope of available information due to the lack of a systematic database. A 2009 study suggested that there were less than 50 health games produced between 1997 and 2007. ${ }^{21}$ A 2011 study indicated that the total number of health games had increased from 45 in 2002 to 104 in $2009 .^{22}$ When the search focuses on studies investigating the efficacy of health games, a 2012 scoping review ${ }^{18}$ identified 149 peer-reviewed research articles studying the efficacy of 166 unique health games available to the healthy public published between 1984 and 2010. A 2014 scoping review of health games developed for health professions contained a survey of around 37 unique health games. ${ }^{9}$

These results may significantly underestimate the total number of games. The disproportionate scarcity of research on health games themselves (compared with their seemingly pervasive existence and huge market potential) underscores the need for a state-of-the-art systematic content analysis of the games themselves to map the landscape of the health game field.

Following the World Health Organization's broad definition of health (originally promulgated in 1948) as "a state of complete physical, mental, and social well-being and not merely the absence of disease or infirmity," ${ }^{, 3}$ we take a similar approach to define games for health by adopting the Robert Wood Johnson Foundation's working definition for this project: games for health refer to "games and game technologies [intended] to improve health and health care."24

\section{Materials and Methods}

To assemble a wide scope of health games, we undertook an extensive process to identify as many eligible games as possible. After consulting with numerous experts in the field of games for health, we decided to use existing international databases for games for health instead of reinventing the wheel by soliciting game entries one by one from potentially thousands of individual health game developers and researchers.

To create the master list of the games, we examined exhaustively the entries from nine international health game online databases: BrainPOP ${ }^{25}$; Health Games Research by Robert Wood Johnson Foundation ${ }^{26}$; Serious Game Classification $^{27}$; Games with Purpose ${ }^{28}$; Games for Change-Health ${ }^{29}$; Playful Learning-Health ${ }^{30}$; Science Game Center ${ }^{31}$; Serious Games Directory-Health Care/Medical ${ }^{32}$; and, Games \& Simulation for Healthcare. ${ }^{33}$ These databases were identified through the following activities conducted between January 1, 2013 and December 31, 2016: discussions held at international health game conferences; inquiries sent to international gaming research listservs, working groups, and website administrators; search engine queries; and personal communication with leading health game experts around the world. We repeated these inquiries until we did not obtain any additional information from the answers.

While we were unable to contact all of the individuals engaged in maintaining the databases with regard to their specific game selection processes (e.g., The Serious Game Directory-Health Care/Medical database was no longer available online in 2017), the historical information we retrieved from the nine database websites provided solid evidence that the content provided by those websites was of high quality and international scope. The information also demonstrated that the game selection process was performed carefully by a group of qualified health game researchers and/or production experts. After reviewing the submission processes of these databases, we consider that the inclusion of a game in a database reflects a certain level of systematic acknowledgement of the game's qualification as a health game.

The online databases we consulted were created between 1999 and 2013 with (on average) more than 10 years of information per database. Five databases originated in the United States ${ }^{26,29-31,33}$; two were produced in Europe (United Kingdom ${ }^{28}$ and France ${ }^{27}$ ); and two came from international organizations based in the United States. ${ }^{25,32}$ All were in English, except for one, which provided both English and French versions. ${ }^{27}$ Most database websites (with one ${ }^{28}$ exception) were advised by one or more researchers with a $\mathrm{PhD}$ in a related field and production staff with extensive game production experience.

At least six databases were funded by research grants from government or nonprofit institutions to create comprehensive online databases for games for health. ${ }^{26,29-33}$ The other three were created by game production companies with a good track record of successful serious game endeavors and a large international user base. ${ }^{25,27,28}$ Most of the websites had a game submission link which allowed individual users to send games over to be reviewed by the staff experts after which the games would be published in the databases. Only one out of the nine databases ceased issuing updates (Health Games Research by Robert Wood Johnson Foundation, as of 2013) for the games in their list during our game extraction process. We are aware that since all of the games we found were in English and based in Western countries, it is possible that our analysis may have missed including games developed in other parts of the world.

All health games indexed in the databases we consulted were included in this project. Several game entries we later determined were in fact game portals (a website containing multiple individual games, e.g., www.fitbrains.com); for these cases, we created individual entries for each game connected to the portal and we removed the original portal entry. Our master list of games was constantly monitored to identify and remove duplicate games to ensure that each entry represented a unique game. Please refer to Figure 1 for the flow chart of the entire game selection and coding process.

We conducted a systematic quantitative content analysis with each game as the unit of analysis. Content analysis is an indigenous communication research method which seeks the objective, systematic, and quantitative description of the manifest content of media and communication. ${ }^{34,35}$ Drawing from the current literature on health game research, usability studies, human-computer interaction, and medical informatics, as well as the indigenous data structure of the nine international health game databases, we developed a systematic coding scheme for each individual game's basic attributes and play information through an iterative process. We utilized a modified version of the Cochrane guidelines for systematic review for this content analysis project to ensure the quality of our protocol. ${ }^{36,37}$ 


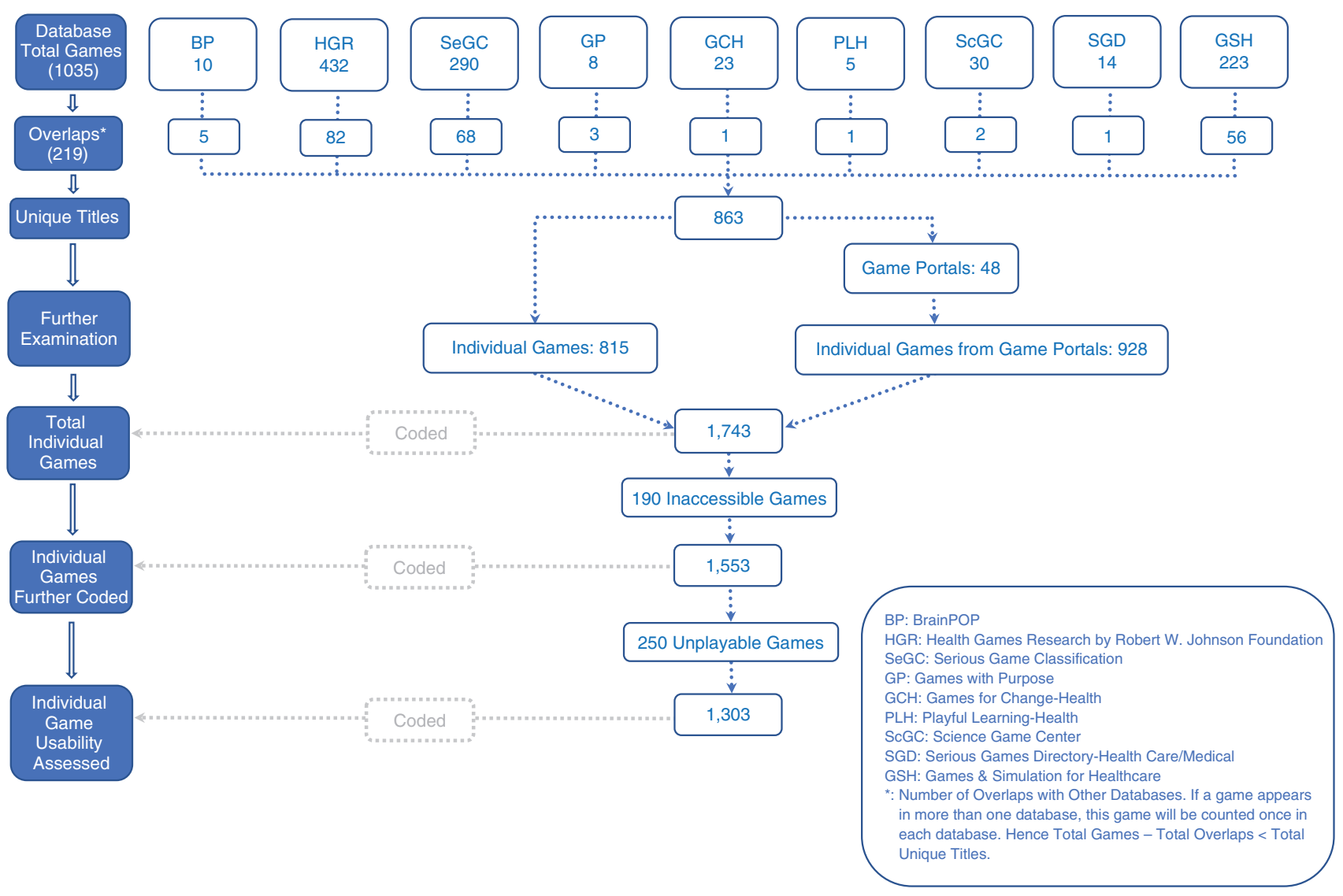

FIG. 1. Flow chart of game selection.

While it is often useful to look for the relevant behavioral and learning theories potentially embedded in games for health, for this project we decided not to focus on identifying specific forms of theory from the games, in large part because, (according to our observations) aside from a limited number of health games used in efficacy studies (less than $10 \%$ of the total number of games), which were accompanied by citations of theories employed in the design of such games, we could not find specific theories which informed the designs of the majority of games from the information we obtained about the games. Assigning a theory to a game based on the coding team's perception would be arbitrary and would not reflect the original design team's ideas. Most of the health games have not been published in peerreviewed academic literature or are decades old, which made difficult the task of finding the original design team and/or their academic partners. For this project, we focused on the tangible aspects and direct play experience by conducting a census of all games for health we could identify.

Game Demographics: The basic attributes are the "demographic"-type of information for each game, including: Game Title, Year of Release, Country of Origin, Target Audience, Platform, Retail Price in U.S. Dollars (which uses the currency exchange rate during the year of release), and Funding Source (Table 1). Information regarding the basic attributes was extracted either through automatic export or manual entry. For databases with the games' basic attributes already in place (e.g., Year of Release), we wrote a script to automatically export relevant information. We conducted the manual entry method for the rest of the games in three stages: (1) when certain information about a game was available on the game's website, we obtained the information from that source website; (2) when there was no website dedicated to an individual game, we conducted an investigative online search for the relevant game developer and publisher websites and blogs, game review sites, online game forum, and any additional online resources to glean information about the games; and, (3) when the first two methods did not yield results, we personally reached out to personnel associated with each game (e.g., designers, sales representatives, marketers, publishers, developers, etc.) through phone, email, online inquiry, fax, or home visits to collect information on individual games.

Game Play Information: The game's play information coding categories were drafted and fine-tuned through multiple game play trials and by referencing existing game coding protocols. ${ }^{38-50}$ The coding categories included: Primary Health Topic (adapted from the World Health Organization's International Classification of Diseases) ${ }^{51}$ Level of Claimed Influence (this refers to the potential influence claimed by the game designers and developers, not their actual influence among players, which is reported by peer-reviewed publications), Internet Connectivity, Game Genre, Sound Presence, Information about Playable Game Characters, Game Perspective, Game Setting, Number of Players, Narrative Presence, Game Play Time, and Game Usability Evaluation. In terms of the criteria for a game's playability evaluation, we adopted the usability principles for videogame design ${ }^{52}$ and modified them 
Table 1. Coding Schemes of Game Demographics and Game Play Information

\begin{tabular}{|c|c|c|}
\hline & Items & Coding scheme \\
\hline \multirow{7}{*}{ 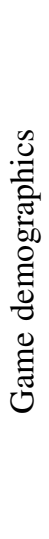 } & Game Title & Name of each game \\
\hline & Year of Release & $\begin{array}{l}\text { The year when the game was first released: If a game has multiple versions } \\
\text { released over time, the coding team would use the earliest release year }\end{array}$ \\
\hline & Country of Origin & Country where the game was originally developed \\
\hline & Target Audience & Healthy general public; Patient; Medical service provider \\
\hline & Platform & $\begin{array}{l}\text { Arcade; Wii (U); Playstation (1-4); Xbox (360 and One); Handheld Console; } \\
\text { Extinct Console; Computers (Windows, Mac, Linux, Sun, Others); Mobile } \\
\text { Device (iPhone, iPad, Android, Others); Web Browser }\end{array}$ \\
\hline & Retail Price in U.S. Dollars & $\begin{array}{l}\text { The foreign currencies were converted to the U.S. Dollars according to the } \\
\text { currency exchange rate during the year of release }\end{array}$ \\
\hline & Funding Source & $\begin{array}{l}\text { Government Research funding; For-profit Organization Research Funding; } \\
\text { Nonprofit Organization Research Funding; Independent Development Funding } \\
\text { (Including individual effort); Other Organization Research Funding; Commer- } \\
\text { cial Game Development }\end{array}$ \\
\hline \multirow{12}{*}{ 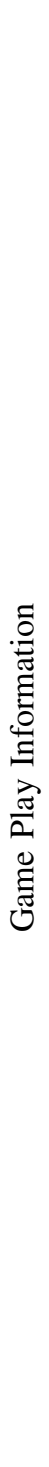 } & $\begin{array}{l}\text { Primary Health Topic } \\
\text { (adopted from Ref. }^{31} \text { ) }\end{array}$ & $\begin{array}{l}\text { Addiction Prevention (Alcohol and other substance abuse); AIDS/STD/Teenage } \\
\text { Pregnancy Prevention; Asthma; Balance; Cancer; Cerebral Palsy; Cognitive } \\
\text { Training; Concussion Prevention; Dental Health; Depression; Diabetes (Type } 1 \\
\text { and 2) and Kidney Disease; Disability; Fetal Alcohol Syndrome; Fracture; } \\
\text { General Health Prevention; Health Education; Hearing Impairment; Medical } \\
\text { Care Provision; Neural Injury; Indirect-Health Education; Nutrition Education } \\
\text { and Eating Disorder; Pain Management; Pelvic Floor Dysfunction; Physical } \\
\text { Activity; Pruritus; Psychiatric Disorder (ADHD/Autism/Anxiety/Bipolar/De- } \\
\text { pression/Phobia/PTSD/Schizophrenia/Stress); Relationship Abuse/Divorce } \\
\text { Support; Sickle Cell Anemia; Spinal Cord Dysfunction; Stroke; Visual } \\
\text { Impairment; Other }\end{array}$ \\
\hline & Level of Influence & Awareness/Knowledge; Intention/Attitude; Behavior/Action \\
\hline & Internet Connectivity & Not Required; Required \\
\hline & Game Genre & $\begin{array}{l}\text { Active/Rhythm; Book; Driving; Fighting; Puzzle; Role-Playing; Shooter; Simple/ } \\
\text { Casual Interactive App; Simulation; Sports; Strategy; Trivia/Quiz; Other }\end{array}$ \\
\hline & Sound Presence & $\begin{array}{l}\text { No Sound; Background Sound/Music Only; Sound Effects Only; Human Voice } \\
\text { Only; Background Sound/Music + Sound Effects; Background Sound/Music + } \\
\text { Human Voice; Sound Effects + Human Voice; Background Sound/Music + } \\
\text { Sound Effects + Human Voice }\end{array}$ \\
\hline & Game Characters & $\begin{array}{l}\text { Playable Game Characters or not; } \\
\text { Number of Characters; } \\
\text { Character Types [Human (Asian, Black, Hispanic, White, Other, Human-Shaped } \\
\text { Alien/Robot, Nonidentifiable, Animal, Plant/Fruit, Nonhuman Shaped Alien/ } \\
\text { Robot, Object, Nonidentifiable, Other)]; } \\
\text { Character Sex (Male, Female, Neutral/Nonidentifiable); } \\
\text { Character Age (Child, Adult, Senior, Nonidentifiable); } \\
\text { Character Health (Always Healthy; Patient from the Start; Becoming Patient in } \\
\text { the End) }\end{array}$ \\
\hline & Game Perspective & $\begin{array}{l}\text { First Person; Third person/2D Bird Eye Top View; Third person/2D/Flat Side } \\
\text { View; Third person/45 Degree View; Third person/Full 3-D; Webpage }\end{array}$ \\
\hline & Game Setting & $\begin{array}{l}\text { Earth/Ground (Inhabited/Uninhabited Continent/Country/City/Island/Building/ } \\
\text { Room); Earth/Water (Ocean, Lake, River); Earth/Air; Earth/Other; Fictitious } \\
\text { planet/place; Known planet (not Earth); Space; Inside Human Body; Unknown/ } \\
\text { Unidentifiable }\end{array}$ \\
\hline & Number of Players & Solo; Double; Multiplayer \\
\hline & Narrative Presence & No; Yes \\
\hline & Game Play Time & In Minute (The time to finish playing a game) \\
\hline & Game Usability Evaluation & $\begin{array}{l}\text { Input Predictability/Customization/Camera Angle/Skippable Content/Input } \\
\text { Scheme/Customizable Control Schemes/Feedback/Instruction/Agent } \\
\text { Behavior }\end{array}$ \\
\hline
\end{tabular}


into a usability criteria chart of game play to evaluate each game by entering 1 to 3 for each criterion (1-Bad, 2-OK, and 3 -Good). Tables 1 and 8 show the coding schemes for the Game Play Information and the Game Usability Rating, respectively. We specifically instructed the coders throughout the training and coding processes to take the era of an older game's production into account when evaluating the game to reduce bias against older games, which could have been limited by the then-current technological advancement.

Between 2013 and 2016, our research team tried to obtain and play as many health games as possible to complete the game play information coding categories. The first author and 11 student coders played and coded each available game in detail. The first author worked closely with the student coders through multiple extensive game coding training sessions and worked with the student coders to revise coding schemes as necessary to achieve substantial to almost perfect agreement among the coders (Kappas: 0.61-1). The intercoder reliability was calculated through multiple iterations as the research team developed the coding scheme that best captures the characteristics of the games included in this analysis. In each iteration, we adopted a slightly improved coding scheme and focused on the sections that produced less-than-ideal Kappas in the previous round.

More specifically, the coders initially did not achieve agreement as often as the authors would have preferred on variables such as "Primary Health Topic" and "Level of Influence," mainly due to a lack of adequate available appropriate categorization for certain games on the part of the research group. For example, a game that emphasized the importance of handwashing would be difficult to fit under any topic from the WHO's disease classification, which formed the basis for the "Primary Health Topic." The "Level of Influence" originally had only "Intention/Attitude; Behavior/Action," which rendered impossible the task of coding games that only provide knowledge of health behavior and are not intended to change disease-related behavior.

The research group therefore decided to add additional categories, such as "General Health Education" and "Awareness/Knowledge," to both variables (respectively) for the next round of coding. Our final coding sheet had over 100 variables. Additional differences were resolved through group discussion until the coding team achieved consensus on an improved version of the meaning of the coding scheme.

If a game was originally released on an extinct console (e.g., Atari ${ }^{\circledR}$ ), the game and its original console were purchased from online auction websites or antique game stores. If a game failed to work with a contemporary operating system (e.g., a Windows 95 game may not function in the current Windows environment), the research team played the game through various gaming emulators. If a game was only temporarily available to a limited audience for a clinical trial, the first author visited the game developer to play the beta version at health game expos or at the game studio. In addition to these efforts, if a game was still unavailable, the research team conducted additional extensive online information search to enter as much information as possible in the coding sheet (e.g., by watching YouTube ${ }^{\circledR}$ and Twitch $^{\circledR}$ websites for video streaming of the game play to gather game information).

To further examine the difference between our games and the games mentioned in efficacy study reports, we conducted some preliminary comparisons between the games for health discussed in peer-reviewed scientific publications and the games identified by our database search.

\section{Results}

\section{Year of release}

We identified a total of 1743 health games released between 1983 and 2016 in 23 countries with their "demographics" coded from the nine international databases. Figure 2 shows the number of games produced over the years. The production of health games gradually increased beginning in 1983 with a sudden surge in 1999. Although there were fluctuations after that, around $70 \%$ of all health games were produced between 2004 and 2013, after which there was a "dip" in the number of releases.

\section{Country of origin}

The United States (Fig. 3) has created 1171 health games (67.18\%), which is significantly more than the runner-up, France, which created 324 games $(18.59 \%)$. A total of 5 countries, Germany (49 games, 2.81\%), Britain (48 games, 2.75\%), Canada (44 games, 2.52\%), Japan (35 games, $2.01 \%$ ), and Sweden (24 games, $1.38 \%$ ) form the third cohort with another 16 countries (a total of 48 games, 2.75\%) constituting the fourth cohort.

\section{Target audience}

The majority of the health games were designed to target the healthy general public (1465 games, $84.05 \%)$; of the remaining games, $153(8.78 \%)$ were designed for medical care providers (e.g., surgeons, nurses) and 125 (7.17\%) for patients with various health problems (e.g., diabetes, cancer).

\section{Platform}

Most of the health games (1529 games, 87.72\%) were released on multiple platforms, making the tabulation of the individual platform for each game difficult. The total percentage of categories, therefore, exceeds 100. A total of 1279 games $(72.38 \%)$ are web browser games that could be played across different platforms. The next most-frequent platform comprised 251 (14.41\%) Windows computer games, followed by 128 (7.34\%) handheld game consoles, 127 (7.29\%) Mac OS games, and 70 (4.01\%) mobile devices. The contemporary TV consoles constituted $4.72 \%$ of the games: 34 $(1.96 \%)$ were on Nintendo $\mathrm{Wii}^{\circledR} ; 29(1.67 \%)$ were on Sony PlayStation $^{\circledR}$; and $19(1.09 \%)$ were on Microsoft Xbox ${ }^{\circledR}$. Of the remaining games, $23(1.28 \%)$ were on early game consoles (e.g., Atari) and 5 (0.23\%) were Arcade games (coinoperated entertainment machine).

\section{Retail price (in U.S. dollars)}

We were able to obtain 1683 (96.56\%) games' retail information (Fig. 4). All foreign currencies were converted to U.S. dollars according to the currency exchange rate during the year of the game release. ${ }^{53}$ If a game is subscription based, we adopted the monthly charge as the retail cost. Almost four of five games $(1379,79.12 \%)$ were free of charge. With regard to the remaining 304 games, the price varied greatly (from $\$ .99$ to $\$ 153,623)$, with over $60 \%$ of them being under $\$ 30$. Since most of the games on the expensive end are for medical care providers, instead of a grand mean, we computed the games' average according to their target audiences. 
FIG. 2. Games by year of release (year, cumulative percentage, number of games).

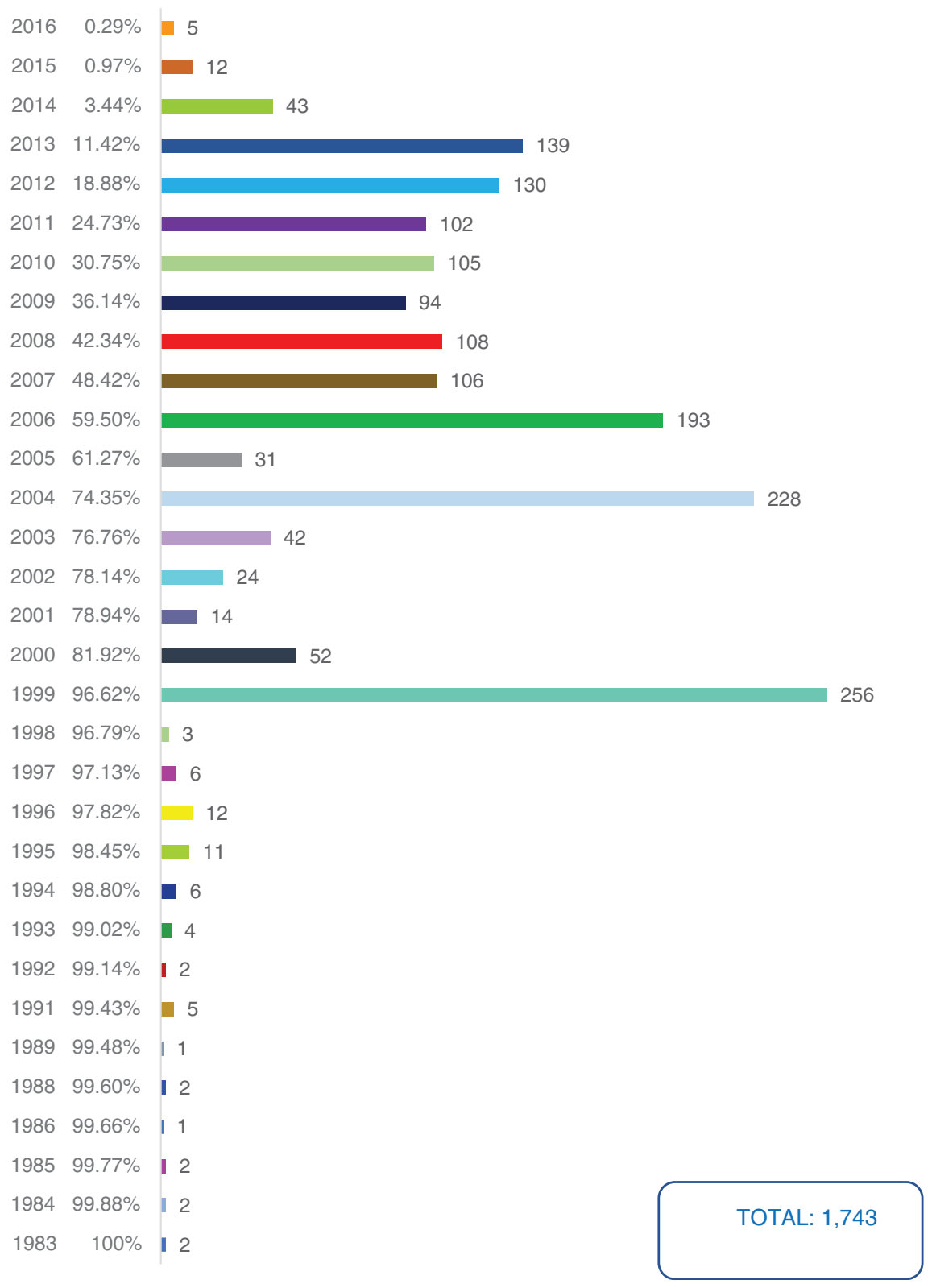

Despite the big variations among the price, the average cost of a game was $\$ 37.83$ for the healthy general public (standard deviation $[\mathrm{SD}]=713.17$ ), \$27.41 for patients with various health problems $(\mathrm{SD}=92.75)$, and $\$ 3235.53$ for medical care providers $(\mathrm{SD}=20,468.53)$. As for the remaining 60 games, 1 was cancelled during the development stage, 4 were still under development, 32 were commissioned only for the funder's own use and not for sale, and retail information regarding the last 23 was unavailable.

\section{Funding source}

In terms of the funding for the 1743 games, $878(50.37 \%)$ were supported by research funding, $109(6.25 \%)$ were sponsored by the government, $531(30.46 \%)$ by nonprofit organizations, and $238(13.65 \%)$ by for-profit organizations (e.g., pharmaceutical companies). Of the remainder, 407 (23.35\%) were funded by commercial game development companies and $458(26.28 \%)$ by independent game developers.
We were able to further code 1553 of the 1743 games $(89.10 \%)$ for additional game information. The rest 190 games were inaccessible. The results are presented below.

\section{Primary health topic}

The most represented health topic (Fig. 5) was cognitive training, for example, games designed to improve cognitive abilities such as working memory and mental rotation $(37.41 \%)$, followed by indirect-health education, or educational games addressing issues indirectly related to disease, such as trash management and understanding the air quality index (13.33\%). Other highly represented health topics included medical care provision $(9.98 \%)$, which included games designed to educate professional medical care providers, such as surgery simulators or doctor-patient communication training, and health education (9.92\%), for example, games for the general public about health issues, such as blood types or DNA. Based on the findings, we expanded the topics to include the following additional entries 


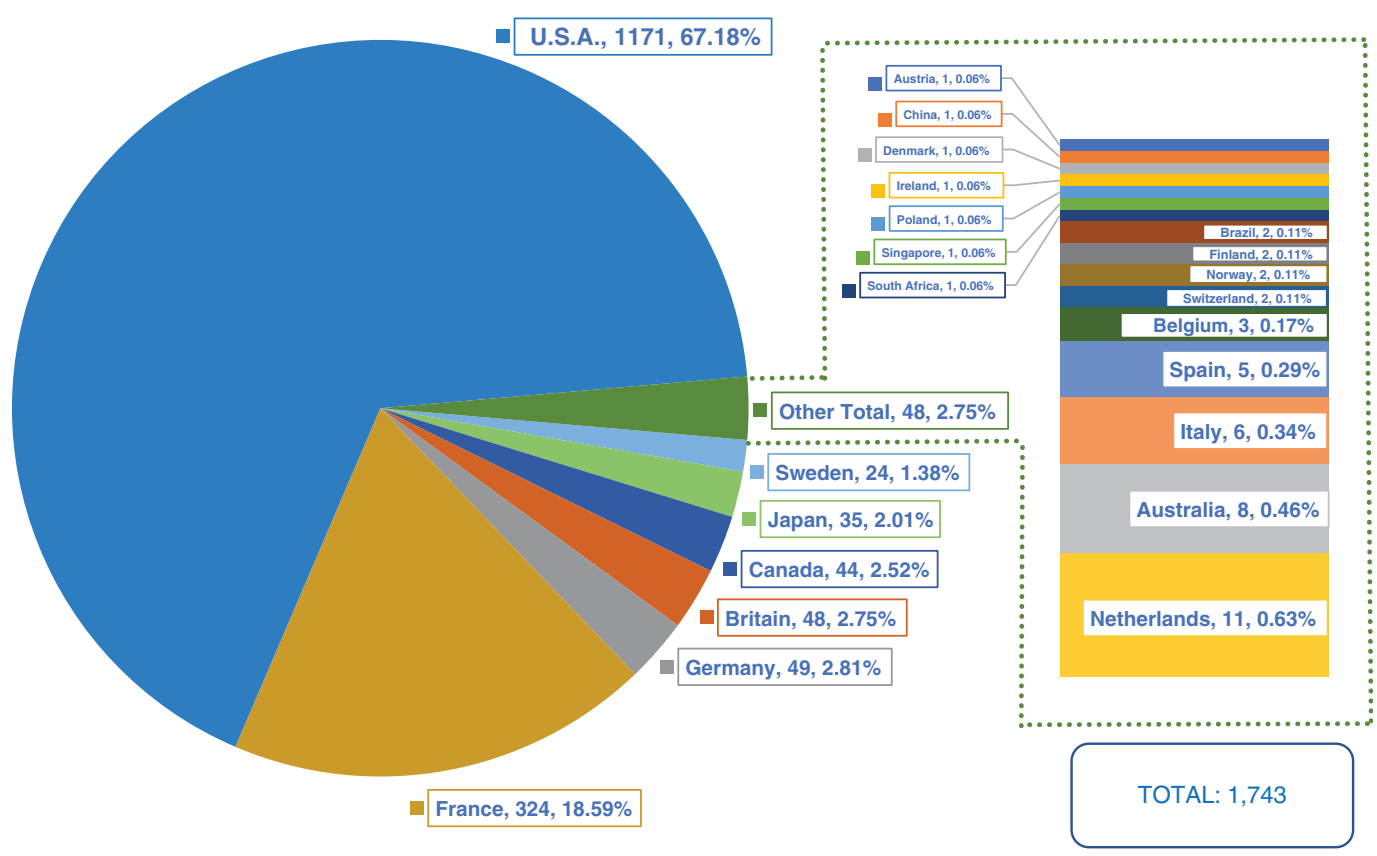

FIG. 3. Games by country of origin (country, number of games, percentage).

for specific health issues: Acne/Skin Care, Cystic Fibrosis, Hormone Replacement Therapy, Infant Health/Shaken Baby Syndrome, Meningitis, Psoriasis, and Yellow Fever.

\section{Level of claimed influence}

We categorized the level of a health game's claimed influence into three levels. The first, Awareness/Knowledge, referred to game which taught the player about a certain health topic (905 games, 58.27\%), for example, understanding blood types or learning human anatomy. Games in the second level (139 games, $8.95 \%)$ are intended to attempt to improve people's behaviors by changing their behavioral intention or attitude toward a certain health issue, for example, encouraging teeth-brushing twice a day or washing hands before eating. The games in the third level (509 games, $32.78 \%$ ) require actual behaviors to play the game, such as active gaming through Wii Console or learning yoga breathing techniques to reduce stress and anxiety.

\section{Internet connectivity}

A total of 831 games $(53.51 \%)$ required an Internet connection for play.

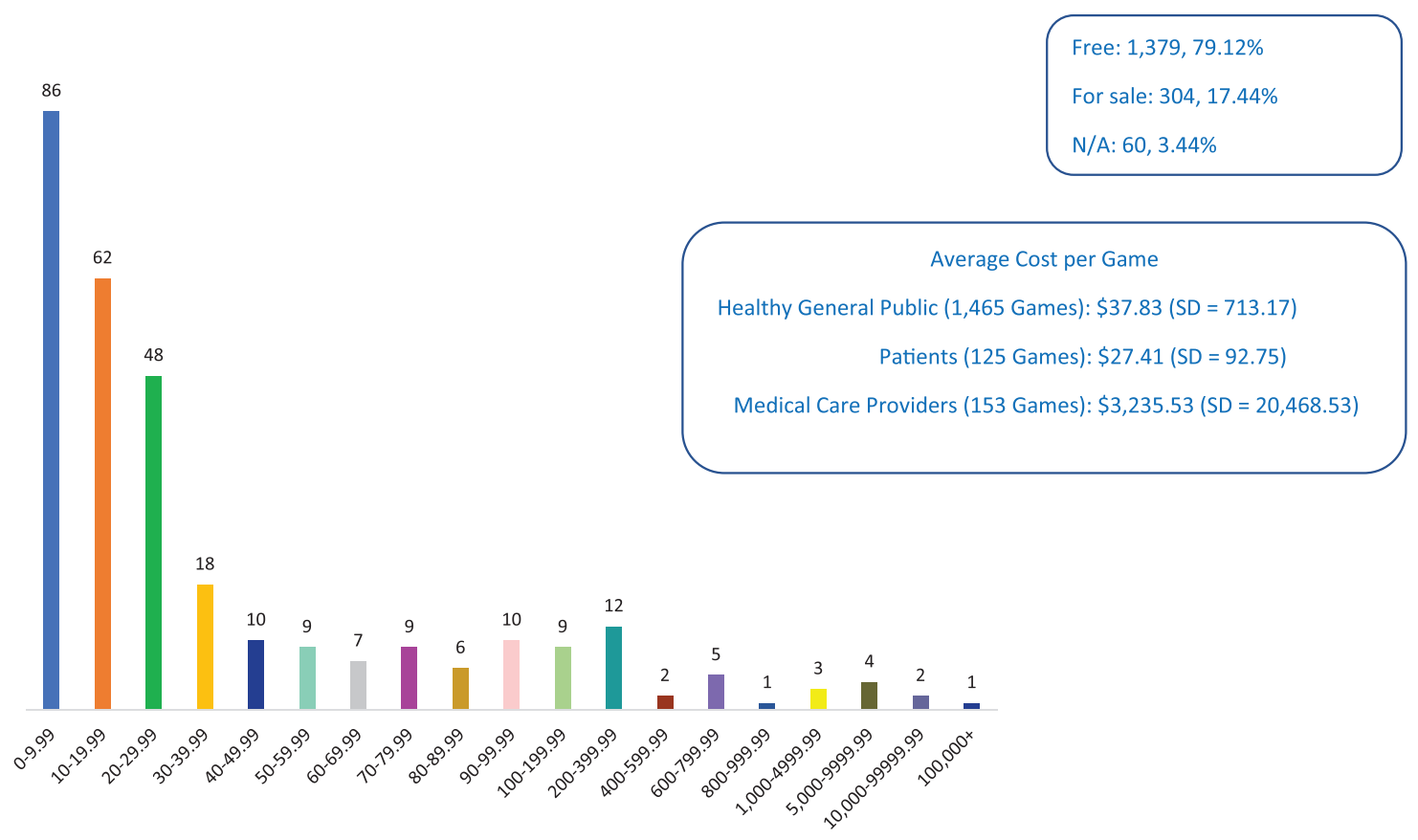

FIG. 4. Retail price for 304 games for sale in U.S. dollars (numbers of games above each bar). 


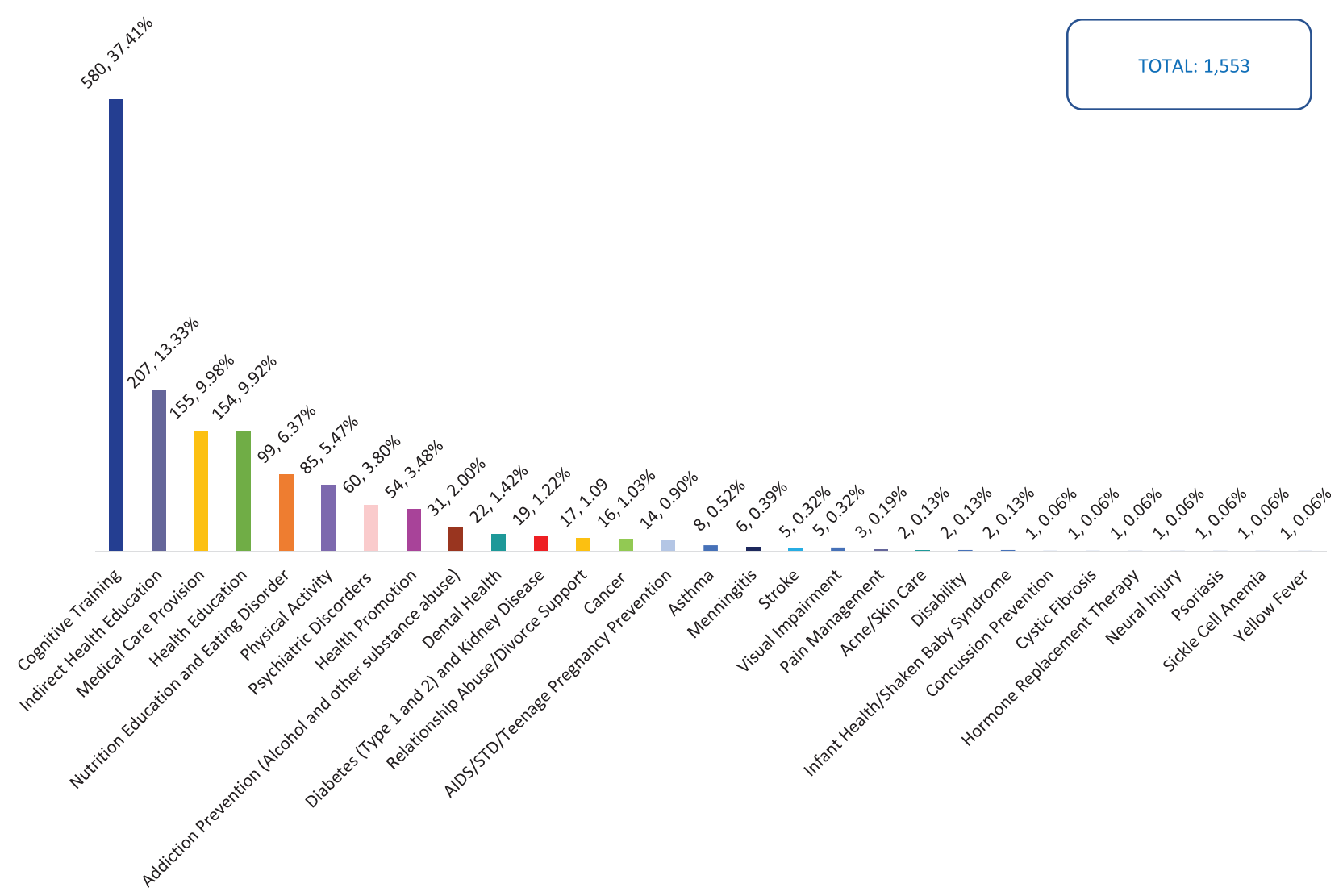

FIG. 5. Games by primary health topics (number of games above each bar, percentage).

\section{Game genre}

We developed a health game genre categorization system after researching existing paradigms. Table 2 presents our definitions along with the number of games in each category. The most popular genre was puzzle games (675 games, $43.46 \%$ ), followed by simple/casual interactive app games (277 games, 17.84\%) and simulation games (195 games, $12.56 \%)$. The least popular game genres included driving (13 games, $0.84 \%$ ) and fighting (2 games, $0.13 \%$ ) games.

\section{Sound presence}

In terms of the sound presence (Table 3), the most popular sound type was sound effects, or sounds caused by player input (454 games, $29.23 \%$ ). Human voice was not a common feature, with only 446 games $(28.72 \%)$ providing some type of human voice. The remaining 284 games (18.29\%) were "mute."

\section{Game characters}

A total of 608 games $(39.15 \%)$ included some types of playable characters; of these games, 431 (27.75\%) featured one character and $177(11.40 \%)$ contained more than one character (Table 4). We conducted further analysis of the playable game characters; for games with more than one character, one character was selected randomly per game. Of those with playable characters, approximately two in three games (402 games, $66.12 \%$ ) featured human or human-like characters and one in three games (206 games, 33.88\%) featured nonhuman or nonhuman-like characters. In terms of the most presented characters, Caucasian characters (209 games) and animals (113 games) were the most prevalent type among human and nonhuman characters.

With regard to character gender, 268 games $(44.08 \%$ of games with characters) featured characters with no information about their gender or customizable gender categories. Of the remaining games, more featured male (220 games, $36.18 \%)$ than female characters (120 games, $19.74 \%)$. As for the age of the characters, except for 214 games $(35.20 \%)$ with nonidentifiable age information or customizable age for the characters, 247 games $(40.63 \%)$ featured adult characters between 18 and 65 years of age, 141 games (23.19\%) featured children under the age of 18 , and only a very few games (6 games, $0.99 \%$ ) featured a senior over the age of 65 .

In terms of character health, over $90 \%$ of the games (563 games) featured characters who were healthy throughout the games, 41 games $(6.74 \%)$ featured characters who were unhealthy or who started as a patient, and 4 games $(0.66 \%)$ featured characters who started as healthy but their health deteriorated over time.

\section{Game perspective}

Except for 27 games (1.74\%), which used a webpage view, and 112 games $(7.21 \%)$ which were played from a first-person perspective, most of the games adopted a third-person perspective. The most prominent type, at a total of 916 games $(58.98 \%)$, was a 2D-Flat Side View similar to the Super Mario Bros game (Table 5). 
Table 2. Number of Games Per Genre $(N=1553)$

Game genre
1. Active/rhythm:
A game that requires the player's body
movement. The game must require
intensive activity from the players to be
categorized as an active/rhythm game.

2. Book/movie:

A game that takes the form of an interactive book or video.

3. Driving:

A game that requires the player to take part in a racing competition with any type of land, air, or sea vehicles.

4. Fighting:

A game that requires the player to control an onscreen character and engage in close combat with the opponent.

5. Puzzle:

A game that emphasizes puzzle solving that involves logic, pattern recognition, sequence solving, and word

completion. Most of the causal games would fall into this category.

6. Role-playing:

A game that requires the player to act as a character and usually involves

some or lots of narrative elements.

7. Shooter:

A game that requires the player to shoot or blow away enemies or objects to let the player character not die and continue gameplay. It mainly tests the player's speed and reaction time.

8. Simple/casual interactive app: These are applications with simple interactive inputs and sometimes can also be called casual games. It can be either a very simple game or an interactive graphic. Example: A game that asks the players to keep a ball in the air.

9. Simulation:

A game with some real world implication/element so that the player's skills in the real world domain will be improved after playing the game. The game can also relate the player to real world issues.

10. Sports:

A game that has an explicit sporting event focus, such as Olympics or NBA etc. The player does NOT have to be physically active to play the game.

11. Strategy:

A game that requires player's autonomous decision-making skills to play and achieve victory.

12. Trivia/quiz:

A game that presents a question/answer or in the form of a quiz show that require players to answer the questions correctly to win.
Table 3. Number of Games per Sound Category

$(N=1553)$

\begin{tabular}{|c|c|c|}
\hline Sound category & Count & $\%$ \\
\hline 1. No sound & 284 & 18.29 \\
\hline $\begin{array}{l}\text { 2. Background sound/music: It does not } \\
\text { have to respond to player input. }\end{array}$ & 26 & 1.67 \\
\hline $\begin{array}{l}\text { 3. Sound effects: Sounds that are caused } \\
\text { by player input. }\end{array}$ & 454 & 29.23 \\
\hline $\begin{array}{l}\text { 4. Human voice: It also includes } \\
\text { utterances by nonhuman-looking } \\
\text { characters as long as it conveys } \\
\text { human language. }\end{array}$ & 37 & 2.38 \\
\hline $\begin{array}{l}\text { 5. 2+3: Background sound/music }+ \text { sound } \\
\text { effects }\end{array}$ & 343 & 22.09 \\
\hline $\begin{array}{l}\text { 6. } 2+4 \text { : Background sound/music }+ \\
\text { human voice }\end{array}$ & 20 & 1.29 \\
\hline 7. $3+4$ : Sound effects + human voice & 00 & 4.38 \\
\hline $\begin{array}{l}\text { 8. } 2+3+4 \text { : Background sound/music }+ \\
\text { sound effects + human voice }\end{array}$ & 321 & 20.67 \\
\hline
\end{tabular}

\section{Game setting}

Most of the games (871 games, 56.08\%) "took place" on Earth, where a room (295 games, 19\%) was the most popular place for the game setting. Slightly more than a third of the games (553 games, $35.61 \%$ ) did not have a specified setting, for example, the background was blank (Table 6).

\subsection{Number of players}

Almost all games (1455 games, 93.69\%) were designed for solo players, with 25 games $(1.61 \%)$ intended for two players and 73 games $(4.7 \%)$ designed for multiple players.

\subsection{Narrative presence}

About one in five games (323 games, 20.80\%) had a narrative plot as part of the design.

\section{Game play time}

The time needed to complete a health game (Table 7) had 19512.56 a large range: 229 games $(14.75 \%)$ did not have a specified ending so could be "played" continuously, such as some app games that required players to enter their daily diet intake, whereas the remaining 1324 games $(85.25 \%)$ could be completed within a time frame of between 1 minute and 80 hours. The research team completed games with a specified ending within an average time of 60.23 minutes $(\mathrm{SD}=276.33)$ and were able to complete $75.66 \%$ of such games within 60 minutes.

After that, we assessed 1303 (83.90\%) of the 1553 games for usability. The rest 250 games were unplayable. The results of this evaluation are described below

\section{Game usability evaluation}

The 1303 playable games were evaluated for their usability attributes using a scoring system $(1=\mathrm{Bad}, 2=\mathrm{OK}$, and $3=$ Good). Table 8 includes the detailed definition of each criterion and presents the average ranking per each category in ascending order. Lower scores indicate that more problems were detected in the specific usability category. "Problem areas" identified include: 
TABle 4. Game Character Information

\begin{tabular}{|c|c|c|c|c|}
\hline Character information & Count & $\%$ & Total & $\%$ \\
\hline \multicolumn{5}{|l|}{ Playable game characters $^{\mathrm{a}}$} \\
\hline \multicolumn{5}{|l|}{ Y̌es } \\
\hline One & 431 & 27.75 & \multirow{2}{*}{608} & \multirow{2}{*}{39.15} \\
\hline More than one & 177 & 11.40 & & \\
\hline No & & & 945 & 60.85 \\
\hline \multicolumn{5}{|l|}{ Character types ${ }^{\mathrm{b}}$} \\
\hline \multicolumn{5}{|l|}{ Human or human-like } \\
\hline Asian & 11 & 2.74 & \multirow{6}{*}{402} & \multirow{6}{*}{66.12} \\
\hline Black & 29 & 7.21 & & \\
\hline Caucasian & 209 & 51.99 & & \\
\hline Hispanic & 16 & 3.98 & & \\
\hline Other (alien, human-looking robot) & 19 & 4.73 & & \\
\hline $\begin{array}{l}\text { Nonidentifiable but human-like } \\
\text { (including characters with } \\
\text { customizable race/ethnicity) }\end{array}$ & 118 & 29.35 & & \\
\hline \multicolumn{5}{|l|}{ Nonhuman or nonhuman-like } \\
\hline Animal (including cell \& bacteria) & 113 & 54.33 & \multirow[t]{5}{*}{206} & \multirow{5}{*}{33.88} \\
\hline Plant/fruit & 5 & 2.40 & & \\
\hline Robot (nonhuman looking) & 11 & 5.29 & & \\
\hline Object (e.g., spaceship, toothbrush) & 57 & 27.40 & & \\
\hline Nonidentifiable (e.g., Pac-Man, monster) & 21 & 10.10 & & \\
\hline \multicolumn{5}{|l|}{ Character sex ${ }^{b}$} \\
\hline \multirow{2}{*}{\multicolumn{3}{|c|}{ Female }} & 120 & 19.74 \\
\hline \multirow{2}{*}{\multicolumn{3}{|c|}{$\begin{array}{l}\text { Male } \\
\text { Nonidentifiable (including characters with customizable sex) }\end{array}$}} & 220 & 36.18 \\
\hline & & & 268 & 44.08 \\
\hline \multicolumn{5}{|l|}{ Character age $\mathrm{b}^{\mathrm{b}}$} \\
\hline \multicolumn{3}{|l|}{ Child (<18 years) } & 141 & 23.19 \\
\hline \multicolumn{3}{|l|}{ Adult (18-65) } & 247 & 40.63 \\
\hline \multicolumn{3}{|l|}{ Senior $(65+)$} & 6 & 0.99 \\
\hline \multicolumn{3}{|c|}{ Nonidentifiable (including characters with customizable age) } & 214 & 35.20 \\
\hline \multicolumn{5}{|l|}{ Character health ${ }^{\mathrm{b}}$} \\
\hline \multirow{2}{*}{\multicolumn{3}{|c|}{ Always healthy (from the start to the end) }} & 563 & 92.60 \\
\hline & \multicolumn{2}{|c|}{ Start as an unhealthy character or as a patient } & 41 & 6.74 \\
\hline \multicolumn{3}{|c|}{ Start as healthy but become unhealthy or a patient in the end } & 4 & 0.66 \\
\hline
\end{tabular}

${ }^{\mathrm{a}} N=1553$.

${ }^{\mathrm{b}} N=608$ (games with playable characters).

- The players were unable to customize a range of setting to accommodate their individual needs (e.g., volume, video setting, game difficulty, control);

- The players were unable to skip some noninteractive or nonplayable content that could include lengthy audio or video sequences (e.g., the introductory opening which presented the background information for a certain health issue);

- The game did not provide sufficient instruction to help players understand how to play it (e.g., no instruction or "help" button was provided when players were confused or unable to figure out how to play the games); and,

- There was a lack of feedback provided to the players regarding their game status (e.g., players spent a while interacting with game elements, but there was no feedback or score change to acknowledge the players' achievement).

Although we instructed the coders to take the historical development of gaming technology into account as they evaluated the games, we also conducted some exploratory analyses to examine whether the usability evolved over time by correlating the usability evaluation with the year of release among the 1303 games (Table 8). Four criteria, Customizable Control Schemes,
Customization, Instruction, and Input Predictability, showed significant positive correlation coefficients suggesting that these aspects improved over time. Counterintuitively, Skippable Content had a weak but significant negative correlation with the Year of Release, suggesting that this aspect has not improved over the years, and perhaps became slightly worse.

Table 5. Number of Games per Visual Perspective Category $(N=1553)$

\begin{tabular}{|c|c|c|}
\hline Visual perspective & Count & $\%$ \\
\hline First-person perspective & 112 & 7.21 \\
\hline \multicolumn{3}{|l|}{ Third-person perspective } \\
\hline $\begin{array}{l}\text { a. 2D-bird's eye view (the movement } \\
\text { of the in-game control will have no } \\
\text { depth beyond the screen vertically) }\end{array}$ & 245 & 15.78 \\
\hline $\begin{array}{l}\text { b. 2D-flat side view (the movement } \\
\text { of the in-game control will be } \\
\text { mostly from side to side) }\end{array}$ & 916 & 58.98 \\
\hline c. 45 Degree view & 90 & 5.8 \\
\hline d. Full 3D & 163 & 10.50 \\
\hline Webpage view & 27 & 1.74 \\
\hline
\end{tabular}




\begin{tabular}{|c|c|c|c|c|}
\hline Locations & Count & $\%$ & Total & $\%$ \\
\hline \multicolumn{5}{|l|}{ Earth } \\
\hline \multicolumn{5}{|l|}{ Ground } \\
\hline \multicolumn{5}{|l|}{ Inhabited } \\
\hline Continent & 30 & 1.93 & 871 & 56.08 \\
\hline Country & 71 & 4.57 & & \\
\hline City & 106 & 6.83 & & \\
\hline Island & 30 & 1.93 & & \\
\hline \multicolumn{5}{|l|}{ Uninhabited } \\
\hline Continent & 39 & 2.51 & & \\
\hline Country & 73 & 4.70 & & \\
\hline City & 3 & 0.19 & & \\
\hline Island & 11 & 0.71 & & \\
\hline Building & 106 & 6.83 & & \\
\hline Room & 295 & 19.00 & & \\
\hline \multicolumn{5}{|l|}{ Water } \\
\hline Ocean & 31 & 2.00 & & \\
\hline Lake & 11 & 0.71 & & \\
\hline River & 9 & 0.58 & & \\
\hline $\begin{array}{l}\text { Air (including } \\
\text { a plane) }\end{array}$ & 23 & 1.48 & & \\
\hline $\begin{array}{l}\text { Other (e.g., a } \\
\text { world map) }\end{array}$ & 33 & 2.12 & & \\
\hline \multicolumn{3}{|c|}{ Other known planet } & 2 & 0.13 \\
\hline \multicolumn{3}{|c|}{ Fictitious planet or space } & 36 & 2.32 \\
\hline \multicolumn{3}{|l|}{ Space } & 21 & 1.35 \\
\hline \multicolumn{3}{|c|}{ Inside human body } & 70 & 4.51 \\
\hline \multicolumn{3}{|c|}{$\begin{array}{l}\text { Unknown/unidentifiable } \\
\text { (e.g., a blank background) }\end{array}$} & 553 & 35.61 \\
\hline
\end{tabular}

\section{Publication versus database game comparison}

We found that approximately half of the games (878 out of 1743) were supported by research funding mechanisms from government, nonprofit, and for-profit research organizations. We also decided to examine the overlap between games we had identified from the databases and those games that were investigated in peer-reviewed research publications. To address this question, we conducted some preliminary comparisons between the games identified from databases and games identified from our 2012 scoping review of publications that explored health game efficacy. ${ }^{18}$

In the scoping review, we identified, from 149 peerreviewed research articles published between 1984 and 2010, a total of 166 unique health games. In comparison, our database search yielded 1310 game entries, a significantly greater number. Of the 166 games, 83 (50\%) overlapped with

Table 7. Game Play Time $(N=1553)$

\begin{tabular}{lrrc}
\hline $\begin{array}{l}\text { Time to finish playing } \\
\text { a game (minutes) }\end{array}$ & Count & \multicolumn{1}{c}{$\%$} & Cumulative\% \\
\hline $1-5$ & 679 & 43.72 & 43.72 \\
$6-10$ & 108 & 6.95 & 50.67 \\
$11-30$ & 227 & 14.62 & 65.29 \\
$31-60$ & 161 & 10.37 & 75.66 \\
$61-90$ & 23 & 1.48 & 77.14 \\
$91-120$ & 53 & 3.41 & 80.55 \\
$121-1200$ & 66 & 4.25 & 84.80 \\
$1200+$ & 7 & 0.45 & 85.25 \\
No end & 229 & 14.75 & 100 \\
\hline
\end{tabular}

our game database search results, $44(26.5 \%)$ were not included in our database results, and $39(23.5 \%)$ were actually off-the-shelf entertainment games released not for health purposes but adopted for research projects. As an example of the off-the-shelf game category, Death Crimson OX (2001), a first-person shooting game, was used for pain distraction on a cold pressor task. ${ }^{54}$ Of the 44 games not included in our databases search results, at least 10 were produced in nonEnglish-language regions, including Korea, Japan, Taiwan, Peru, Mexico, and Switzerland.

\section{Discussion}

To the extent of our knowledge, this is the first attempt to provide a historical scoping overview of health games on an international basis. Our study protocols and methods provide a comprehensive systematic analytic framework for health games, despite the challenges we faced due to the lack of a global health game directory (none of the nine databases contained a significant portion of the games).

While game production appears to have slowed since 2014, resulting in a "dip" (Fig. 2), there has been an overall increase in global health game production since the 1980s. Most of the growth occurred around and after the turn of the millennium, suggesting the confluence of games for health and digital technology, resulting in an exponential growth in the number of games. Since all of the health games analyzed in this project were identified through database searches with a search end date of December 31, 2016, the dip could have resulted from database entry lag time for a game developed in recent years, or, with more health games emerging from more platforms (e.g., mobile apps), some databases might simply have ceased to update game entries because the database creators' own definition did not include these platforms.

Another reason for the dip might be related to market saturation issues. Since most of these games were free or cost at most a nominal amount, the new game designers interested in a certain health topic may either have been discouraged by the superfluous amount of games on the same topic or by the lack of potential profit. Last but not least, a potential explanation for the post-2014 dip may have been the controversy of cognitive training games, which constituted more than $37 \%$ of all games. Since 2014, several research groups have questioned the efficacy of cognitive training games ${ }^{55-57}$ and several game producers have paid multimillion dollar settlements as a consequence of false advertisement lawsuits. Accordingly, we also found a significant drop in the number of cognitive training games since 2014 when compared with previous years.

In terms of the "birth place" of the health games we assessed, the U.S. tops the country list as the origin of two out of three games intended to be played for health-related reasons. France claims a firm second place, with almost $20 \%$ of the global production. The French government's support of the French gaming industry could play a major part in this achievement. In 2003, the French Ministry of Culture offered 4 million euros to assist aspiring game developers, ${ }^{58}$ and in 2016 the French Parliament voted to increase the rate of tax credit up to 6 million euros per game company. ${ }^{59}$ Consequently, France is the second highest achiever in the world for the production of videogames overall. ${ }^{60}$ On a grander scale, North America ( 2 countries) is the main source of 
Table 8. Game Usability Rating (Ranked in an Ascending Order) and Bivariate Correlation Coefficient (R) With Year of Release (Score: 1/Bad; 2/OK; 3/Good) $(N=1303$ )

\begin{tabular}{|c|c|c|c|}
\hline Game usability criteria & Score (SD) & $\mathrm{R}$ & $\mathrm{P}$ \\
\hline $\begin{array}{l}\text { 1. Customizable control schemes: How well does the game provide customizable control } \\
\text { schemes? }\end{array}$ & $1.08(0.37)$ & 0.11 & $<0.001$ \\
\hline $\begin{array}{l}\text { 2. Customization: How well does the game allow users to customize game settings such as } \\
\text { video or audio, difficulty level, game speed, etc.? }\end{array}$ & $1.70(0.92)$ & 0.18 & $<0.001$ \\
\hline $\begin{array}{l}\text { 3. Skippable content: How well does the game allow users to skip nonplayable and } \\
\text { frequently repeated content? }\end{array}$ & $2.52(0.79)$ & -0.08 & 0.004 \\
\hline $\begin{array}{l}\text { 4. Instruction: How well does the game provide instructions, training, and help to the } \\
\text { players? }\end{array}$ & $2.70(0.60)$ & 0.15 & $<0.001$ \\
\hline $\begin{array}{l}\text { 5. Feedback: How well does the game provide users with information on game status/ } \\
\text { feedback? }\end{array}$ & $2.76(0.52)$ & - & n.s. \\
\hline $\begin{array}{l}\text { 6. Input predictability: How well does the game respond predictably to the player's inputs/ } \\
\text { actions? }\end{array}$ & $2.83(0.45)$ & 0.08 & 0.004 \\
\hline $\begin{array}{l}\text { 7. Input scheme: How well does the game provide an input scheme? (i.e., Clumsy or not? It } \\
\text { should provide controls that are easy to manage, and that have an appropriate level of } \\
\text { sensitivity and responsiveness) }\end{array}$ & $2.90(0.36)$ & - & n.s. \\
\hline $\begin{array}{l}\text { 8. Agent behavior: How well does the game provide predictable and reasonable behavior } \\
\text { for computer-controlled agents (i.e., any artificial intelligence problems)? }\end{array}$ & $2.91(0.32)$ & - & n.s. \\
\hline $\begin{array}{l}\text { 9. Camera angle: How well does the game provide a good match between the camera } \\
\text { angle and the action? (i.e., nonobstructed views that are appropriate for the user's } \\
\text { current actions) }\end{array}$ & $2.96(0.22)$ & - & n.s. \\
\hline
\end{tabular}

global health game production, followed by Europe (16 countries), Asia ( 3 countries), Africa (1 country), South America (1 country), and Oceania (1 country). As health and healthcare are increasingly becoming global issues, more games for health should be "born" in more countries and on more continents. It is worth mentioning here that these comments have the caveat that our results are limited by our sampling strategy: all of the databases we used come from the United States, France, and the United Kingdom and all of the databases are in English. Additional comments can be found in the limitation discussion.

More than $84 \%$ of the games were designed for the healthy general public, which reflected the role health games could play in preventive healthcare. This can be further deduced from the primary health topics the games covered, most of which (e.g., health education, nutrition and physical activity, substance abuse, diabetes) focused on noncommunicable diseases that could be prevented or controlled with behavior changes. While the effects of some cognitive training games may still be debatable, it is more important to focus on the power of games to instigate real changes in players' realworld behavior on a broader scale. Games could offer a significant potential opportunity for health promotion in the general population. It is equally exciting to see that almost $10 \%$ of all health game topics involved the training and educating of medical care providers. These offer additional opportunities for the students as well as those already working to improve their skill and knowledge. Perhaps more health topics and disease will be targeted in future game development.

Most of the games $(79.12 \%)$ were free, echoing the prosocial nature of the games intended to be used for health. The majority of them were web-based browser games supported by multiple devices such as computers and smart phones. This suggests that health games are becoming inexpensive and increasingly accessible (given the growing market for affordable personal computing and handheld mobile devices) to the general public. However, we cannot assume that these prosocial creative endeavors are pro bono in nature, as around $36 \%$ of the games were funded by the government or nonprofit organizations. It is unclear if this type of pricing model will limit the size of development and growth for the rest of the games $(64 \%)$ from for-profit organizations, including independent and commercial game developers.

Moreover, three in four games could be completed within an hour of play, almost $60 \%$ of them only stayed at the level of raising awareness and knowledge delivery, only a relatively few games were equipped with a human voice (28\%) and $18 \%$ were completely mute. More than $50 \%$ of the games were puzzle or simple casual interactive applications instead of engaging the player in an activity of longer duration or being constructed with more technical sophistication. These prevalent health game specifications raise a critical question about their impact: Should health games go beyond these limitations to instigate more significant changes in the players thus opening new opportunities for funding and commercialization?

The high prevalence of human-shaped characters suggested homophily in character design. While around $30 \%$ of characters had customizable ethnicities, $45 \%$ of characters had a modifiable gender, and $36 \%$ of characters had customizable age, the remaining character demographics reflected similar patterns in nonhealth games. ${ }^{38}$ Diversity remained an issue: Caucasians, male gender, and adults were overrepresented. Only $7 \%$ of the games were designed for patients and only around $7 \%$ of the game characters were patients. Games for health as a field of endeavor should be more inclusive of patients and minorities, since these groups equally (if not more) need games to improve their quality of life.

The pricing for games for medical care providers was much higher than that for the general public and patients. While this seemed to be easily incorporated into the medical institution's overall expense, the pricing structure could still be prohibitive for those in the market who work in developing countries. Further research is needed to find the 
balance for the healthy growth of the health game market so that the games will be affordable while still supporting the developers' sustainable development.

While health games generally have not had a comparable development investment when compared with the AAA games (i.e., games with the highest development budgets, quality, and levels of promotion), ${ }^{61}$ it should not mean that games for health should naturally fall short in terms of usability criteria. Given the current prevalence of videogaming, a health game player may have already experienced years of commercially developed entertainment games before playing a game for health. Not attending to common design issues such as customization, skippable content, instruction, and feedback may push potential users away and minimize the potential prosocial impact.

With technological advancement, while usability criteria such as Customizable Control Schemes, Customization, Instruction, and Input Predictability may have improved over time, health game designers appear to have become increasingly reluctant to let the players skip the nonplayable content such as elaborate cutscenes (i.e., sequences in a videogame that are not interactive). Users should be afforded with the freedom to engage with the games at their own pace. Additionally, over $90 \%$ of the games were designed for one user only. Weaving more social elements into the game design may help connecting more players in a meaningful way (e.g., patients suffering from the same disease battling a common enemy).

Our results are not without limitations. All of the games we assessed were extracted from health game databases not directly from the market, as we wanted to ensure that a given game was indeed recognized as a health game. However, to our knowledge, there has been no official organization that has the authority to label a game as a "health game." The recent controversy in cognitive training game companies' claim of brain health benefits made us resort to health game databases instead of following the marketing packages of games.

The key limitation of these databases is that more recent games might not have been recorded, or they might have been entered without accurate information, or some nonEnglish games have not been entered into the database. The research team conducted several rounds of extensive information searches with the goal of reducing potential errors. Since we are not aware of any general estimates of how many games for health have been created, we were unsure of the number of games potentially missing from the databases. We would like to note, however, that the total number of games we identified was significantly greater than the numbers we derived from published systematic reviews or estimates.

Another limitation is that the databases were based in the Western world and thus may have omitted games from Asian-Pacific regions, which are expected to be the fastest growing regions for the serious games market, ${ }^{2}$ and games from other non-English speaking countries, The Netherlands, for example, although considered to be "in the West" and an important player in global serious game industry, ${ }^{62}$ may not be fully represented in the database. We were unable to discover non-English health game databases or directories. Similar indexing efforts for games made in these areas of the world should be dedicated to creating additional databases.
In addition, while we tried our best to capture as many games as possible from the databases, our list of games may have missed games developed by individual researchers that were not entered into the databases. Perhaps instead of the multiple database approach, a systematic international effort should be directed to creating one up-to-date database that allows researchers, practitioners, and the interested public to submit games. Of note, all online databases allow individual serious game designers and researchers to submit entries and to suggest games to be included, permitting their health games to reach a larger audience.

It is also worth mentioning that the data structure for our study reflects the fact that our work is an environmental scan ${ }^{63}$ of existing games, not a historical review and examination of the progression of the field over the years. For example, we did not focus on evaluating the effect of technological advancement on the features and influences of health games developed over the last three decades (e.g., advancements in rendering techniques, haptic interfaces, sound synthesis, etc.).

Last but not least, our preliminary comparison between the health games from the databases and those identified from academic publications reveals an interesting dilemma: While our database search yielded a far larger sample of games as opposed to those identified from publications, 1310 versus 166 , only half of the latter could also be found in the former. The reasons for the difference are twofold: (1) as mentioned before, our U.S.-centric English database search might have failed to include games made in the rest of the world; and, (2) a game not originally intended to be a health game may become one when it is used in a health context by researchers. The same questions remain: What counts as a game for health exactly? Should we depend on the perspectives of designers? Or those of players? Or of the researchers who adopt and use them for publication? There seems to be no consensus among the health game producers, practitioners, and researchers around the world, which suggests that a systematic international effort should also be dedicated to crafting a consensus regarding the exact definition of games for health as well.

\section{Conclusion}

Despite the limitations of our results, our study offers the first mapping on a global basis of the current scope of health games. We have systematically described the "demographics" of games, including their play features and usability issues, and we described the extent to which our results overlapped with those of recent game efficacy studies. Our findings raise critical issues about features that could affect the future of health game design and research. We suggest that there is a need for an in-depth international collaboration across broader global scopes as well as to revisit fundamental issues such as the definition of games for health. Health games have developed greatly over the last decades. More unified and systematic effort should be devoted to create a well-organized description of health games that is informative, inclusive, and inspiring.

\section{Acknowledgments}

This project was partially funded by a grant from the National Institute of Diabetes and Digestive and Kidney Diseases (1R01DK109316-01), The narrative effect of active 
video games on long-term moderate-to-vigorous physical activity, PI: A.S.L., and by a Northeastern University College of Arts, Media, and Design (CAMD) Faculty Research and Creative Activity Incentive Grant (FRCAIG), A virtual census of health game characters, PI: A.S.L. The acquisition of games was partially funded by the School of Communication at Northwestern University, Evanston, IL, and the College of Arts, Media, and Design and Bouvé College of Health Sciences at Northeastern University, Boston, MA.

\section{Author Disclosure Statement}

No competing financial interests exist.

\section{References}

1. Ritterfeld U, Cody M, Vorderer P. Serious Games: Mechanisms and Effects. New York: Routledge; 2010.

2. Marketsandmarkets.com. Serious Game Market by Vertical (Education, Corporate, Healthcare, Retail, Media and Advertising), Application (Training, Sales, Human Resource, Marketing), Platform, End-User (Enterprise, Consumer), and Region-Forecast to 2020. 2015. www.marketsandmarkets .com/Market-Reports/serious-game-market-67640395.html (accessed December 17, 2015).

3. Digi-Capital. Inc., Global Games Investment Review. 2017. www.digi-capital.com/reports/\#global-games-investmentreview (accessed August 20, 2017).

4. Michael D, Chen S. Serious Games: Games That Educate, Train, and Inform. Boston, MA: Cengage Learning, Inc; 2006.

5. Robert Wood Johnson Foundation. The Games for Health Project. 2004. www.rwjf.org/en/how-we-work/grants/grantees/ GamesforHealth.html (accessed December 7, 2015).

6. Entertainment Software Association. 2017 Essential Facts about the Computer and Video Game Industry. 2017. www .theesa.com/wp-content/uploads/2017/06/!EF2017_Design_ FinalDigital.pdf (accessed August 29, 2017).

7. Kaiser Family Foundation. Generation M2: Media in the Lives of 8- to 18-Year-Olds. 2010. www.kff.org/entmedia/ upload/8010.pdf (accessed May 18, 2010).

8. Greenwald W. Kinect vs. PlayStation Move vs. Wii: MotionControl Showdown. 2010. www.pcmag.com/article2/0,2817, 2372244,00.asp (accessed February 12, 2011).

9. Ricciardi F, De Paolis LT. A comprehensive review of serious games in health professions. Int J Comput Games Technol 2014; 11:41-51.

10. Arnab S, Dunwell I, Debattista K. Serious Games for Healthcare: Applications and Implications. Vol Hershey, PA: IGI Global; 2013.

11. Kato PM. Video games in health care: Closing the gap. Rev Gen Psychol 2010; 14:113-121.

12. Anguera JA, Boccanfuso J, Rintoul JL, et al. Video game training enhances cognitive control in older adults. Nature 2013; 501:97-101.

13. Baranowski T, Baranowski J, Thompson D, et al. Video game play, child diet, and physical activity behavior change a randomized clinical trial. Am J Prev Med 2011; 40:33-38.

14. Brown SJ, Lieberman DA, Gemeny BA, et al. Educational video game for juvenile diabetes: Results of a controlled trial. Med Inform 1997; 22:77-89.

15. Kato PM, Cole SW, Bradlyn AS, Pollock BH. A video game improves behavioral outcomes in adolescents and young adults with cancer: A randomized trial. Pediatrics 2008; 122: e305-e317.
16. Rosser JC, Jr., Lynch PJ, et al. The impact of video games on training surgeons in the 21st century. Arch Surg 2007; 142:181-186.

17. DeSmet A, Van Ryckeghem D, Compernolle S, et al. A meta-analysis of serious digital games for healthy lifestyle promotion. Prev Med 2014; 69:95-107.

18. Kharrazi H, Lu AS, Gharghabi F, Coleman W. A scoping review of health game research: Past, present, and future. Games Health J 2012; 1:153-164.

19. Lu AS, Kharrazi H, Gharghabi F, Thompson D. A systematic review of health videogames on childhood obesity prevention and intervention. Games Health J 2013; 2:131-141.

20. Primack BA, Carroll MV, McNamara M, et al. Role of video games in improving health-related outcomes. Am J Prev Med 2012; 42:630-638.

21. Ratan R, Ritterfeld U. Classifying serious games. In: Ritterfeld U, Cody M, Vorderer P, eds. Serious Games: Mechanisms and Effects. New York: Routledge; 2009:10-24.

22. Djaouti D, Alvarez J, Jessel J-P, Rampnoux O. Origins of serious games. In: Ma M, Oikonomou A, Jain LC, eds. Serious Games and Edutainment Applications. London: Springer; 2011:25-43.

23. World Health Organization. Constitution of the World Health Organization. 1948. www.who.int/about/mission/en/ (accessed March 23, 2017).

24. Games for Health Project. About The Games for Health Project. 2004-2017. https://gamesforhealth.org/about/ (accessed March 23, 2017).

25. BrainPOP-Health. 2016. www.brainpop.com/games/gamefinder/?subject=Health (accessed December 31, 2016).

26. Health Games Research by Robert Wood Johnson Foundation. 2013. www.healthgamesresearch.org/db/search/tab= games\# (accessed January 2, 2014).

27. Serious Game Classification. 2016. http://serious.game classification.com/EN/search/taxonomy.html?search[]=\& search[]=Healthcare\&mode=least\#results (accessed December 31, 2016).

28. Games with Purpose-Health. 2016. http://gameswithpurpose .org/tag/health/ (accessed December 31, 2016).

29. Games for Change-Health. 2016. www.gamesforchange.org/ game_categories/health/ (accessed December 31, 2016).

30. Playful Learning-Health. 2015. http://beta.playfullearning. com/games (accessed January 1, 2014).

31. Science Game Center. 2016. www.sciencegamecenter.org/ games (accessed December 31, 2016).

32. Serious Games Directory-Health Care/Medical. 2015. www .seriousgamesdirectory.com/proj/health-care-medical (accessed February 2, 2014).

33. Games \& Simulation for Healthcare. 2015. http://health caregames.wisc.edu/search_results.php?vendor $=\&$ audience $=$ $\&$ platform $=\&$ topic $=\&$ keyword $=\&$ Search $=$ Submit + Query (accessed December 31, 2016).

34. Berelson B. Content Analysis in Communication Research. Glencoe, IL: Free Press; 1952.

35. Krippendorff K. Content Analysis: An Introduction to Its Methodology. Thousand Oaks, CA: Sage; 2012.

36. Moher D, Liberati A, Tetzlaff J, et al. Preferred reporting items for systematic reviews and meta-analyses: The PRISMA statement. PLoS Med 2009; 6:e1000097.

37. Higgins JP, Green S. Cochrane handbook for systematic reviews of interventions. Vol. 4. West Sussex, England: John Wiley \& Sons; 2011.

38. Williams D, Martins N, Consalvo M, Ivory JD. The virtual census: Representations of gender, race and age in video games. New Media Soc 2009; 11:815-834. 
39. Zagal JP, Mateas M, Fernández-Vara C, et al. Towards an ontological language for game analysis. Changing Views: Worlds in Play. Proceedings of Digital Games Research Association Conference; 2007.

40. Combs SE. Video Games and Violence: A Content Analysis of Print Advertisements and Internet Trailers. Tuscaloosa, AL: University of Alabama Libraries; 2010.

41. Dahlskog S, Kamstrup A, Aarseth E. Mapping the game landscape: Locating genres using functional classification. Breaking New Ground: Innovation in Games, Play, Practice and Theory. Proceedings of Digital Games Research Association Conference; 2009.

42. Dubbels B. Gamification, serious games, ludic simulation, and other contentious categories. Int J Gaming Comput Mediated Simul 2013; 5:1-19.

43. Bjbrk S, LundQren S, Holopainen J. 15. Game design patterns. Paper presented at: Level up: Digital Games Research Conference, 4-6 November, 2003, Utrecht University; 2003.

44. Martins N, Williams DC, Harrison K, Ratan RA. A content analysis of female body imagery in video games. Sex Roles 2009; 61:824-836.

45. Consalvo M. Videogame Content: Game, Text, or Something Else. The International Encyclopaedia of Media Studies: Media Effects/Media Psychology, Blackwell Publishing Ltd. 2013. www academia edu/1561516/Videogame_Content_ Game_Text_or_Something_El se (accessed March 18, 2014).

46. Bullen T, Katchabaw M, Dyer-Witheford N. Automating content analysis of video games. Loading 2007; 1. Available at http://journals.sfu.ca/loading/index.php/loading/ article/download $/ 5 / 2$

47. Grace LD. Affection Games in Digital Play: A Content Analysis of Web Playable Games. Paper presented at: DiGRA Conference; 2013.

48. Juul J. Swap adjacent gems to make sets of three: A history of matching tile games. Artifact 2007; 1:205-216.

49. Consalvo M, Dutton N. Game analysis: Developing a methodological toolkit for the qualitative study of games. Game Stud 2006; 6:1-17.

50. Brand JE, Knight SJ. The Diverse Worlds Project: Narrative, Style, Characters and Physical World in Popular Computer and Video Games. 2003. https://works.bepress. com/scott_knight/1/ (accessed January 1, 2014).

51. World Health Organization (WHO). International Classification of Diseases:[9th] Ninth Revision, Basic Tabulation List with Alphabetic Index. Geneva: World Health Organization; 1978.

52. Pinelle D, Wong N, Stach T. Heuristic evaluation for games: Usability principles for video game design. Paper presented at: Proceedings of the SIGCHI Conference on Human Factors in Computing Systems; 2008.

53. XE Currency Converter. XE Currency Converter. 2017. www .xe.com/ (accessed December 20, 2016).
54. Raudenbush B, Koon J, Cessna T, McCombs K. Effects of playing video games on pain response during a cold pressor task. Percept Motor Skills 2009; 108:439-448.

55. Merzenich M. Cognitive Training Data. 2016. www.cognitive trainingdata.org (accessed March 8, 2017).

56. Simons DJ, Boot WR, Charness N, et al. Do "braintraining” programs work? Psychol Sci Public Interest 2016; 17:103-186.

57. Underwood E. Neuroscientists speak out against brain game hype. Science 2014. www.sciencemag.org/news/2014/10/ neuroscientists-speak-out-against-brain-game-hype (accessed January 2, 2017).

58. Hermida A. France Offers Grants for Games. 2003. http:// news.bbc.co.uk/2/hi/technology/3084677.stm (accessed March 8, 2017).

59. Audureau W. Le crédit d'impôt jeu vidéo à $30 \%$ adopté par l'Assemblée nationale. 2016. www.lemonde.fr/economie/ article/2016/11/17/le-credit-d-impot-jeu-video-a-30-adoptepar-1-assemblee-nationale_5033133_3234.html (accessed March 8, 2017).

60. Rangi M. France Is Second in the World for the Production of Video Games. 2014. www.diplomatie.gouv.fr/en/frenchforeign-policy/economic-diplomacy-foreign-trade/events/ article/france-is-second-in-the-world-for (accessed March 8, 2017).

61. DeMaria R, Wilson JL. High Score!: The Illustrated History of Electronic Games. Berkeley, CA: McGraw-Hill Osborne Media; 2003.

62. IGN Staff. The Netherlands Announces Its Growing Role in the Global Games Industry. 2008. Available at: http://www .ign.com/articles/2008/05/07/the-netherlands-announces-itsgrowing-role-in-the-global-games-industry Accessed September 3, 2017.

63. Morrison JL. Environmental scanning. In: Whitely MA, Porter JD, and Fenske RH, eds. A Primer for New Institutional Researchers. Tallahassee, FL: The Association for Institutional Research; 1992:86-99.

Address correspondence to:

Amy Shirong Lu, PhD

Health Technology Laboratory

Department of Communication Studies College of Arts, Media \& Design

Department of Health Sciences

Bouvé College of Health Sciences

Northeastern University 360 Huntington Ave 212A Lake Hall Boston, MA 02115

E-mail: a.lu@northeastern.edu 